\title{
Association of Maternal Diabetes Mellitus and Polymorphisms of the NKX2.5 Gene in Children with Congenital Heart Disease: A Single Centre-Based Case-Control Study
}

\author{
Mingyi Zhao $\mathbb{D}$, ${ }^{1}$ Jingyi Diao $\mathbb{D},{ }^{2}$ Peng Huang $\mathbb{D}^{3}{ }^{3}$ Jinqi Li $\mathbb{D}^{2},{ }^{2}$ Yihuan Li $\mathbb{D},{ }^{2}$ Yang Yang $\mathbb{D},{ }^{1}$ \\ Liu Luo $₫{ }^{2}$, Senmao Zhang $\left({ }^{2},{ }^{2}\right.$ Letao Chen $₫$, , Tingting Wang $₫{ }^{2}$, Ping Zhu $₫{ }^{4}$, \\ and Jiabi Qin (iD) $2,4,5$ \\ ${ }^{1}$ Department of Pediatrics, The Third Xiangya Hospital, Central South University, Changsha, Hunan, China \\ ${ }^{2}$ Department of Epidemiology and Health Statistics, Xiangya School of Public Health, Central South University, Changsha, \\ Hunan, China \\ ${ }^{3}$ Department of Cardiothoracic Surgery, Hunan Children's Hospital, Changsha, Hunan, China \\ ${ }^{4}$ Guangdong Cardiovascular Institute, Guangdong Provincial People's Hospital, Guangdong Academy of Medical Sciences, \\ Guangzhou, Guangdong, China \\ ${ }^{5}$ National Health Commission Key Laboratory for Birth Defect Research and Prevention, Changsha, Hunan, China
}

Correspondence should be addressed to Ping Zhu; tanganqier@163.com and Jiabi Qin; qinjiabi123@163.com

Received 23 May 2020; Revised 19 July 2020; Accepted 4 August 2020; Published 26 September 2020

Guest Editor: Gaetano Santulli

Copyright (C) 2020 Mingyi Zhao et al. This is an open access article distributed under the Creative Commons Attribution License, which permits unrestricted use, distribution, and reproduction in any medium, provided the original work is properly cited.

Background. Congenital heart disease (CHD) is one of the most common birth defects among newborns, accounting for a large proportion of infant mortality worldwide. However, the mechanisms remain largely undefinable. This study aimed to investigate the association of CHD in offspring of mothers with diabetes mellitus (DM) and single nucleotide polymorphisms (SNPs) of NKX2.5. Methods and Results. A case-control study of 620 mothers of CHD patients and 620 mothers of healthy children admitted to Hunan Children's Hospital from November 2017 to December 2019 was conducted. We collected the mothers' information by questionnaire and detected children's NKX2.5 variants with a MassARRAY system. The interaction coefficient $(\gamma)$ was used to quantify the estimated gene-environment interactions. Univariate and multivariate analyses both showed that the infants had a higher risk of CHD if their mothers had a history of DM, including gestational DM (GDM) during this pregnancy (adjusted odds ratio $[\mathrm{aOR}=4.98]), \mathrm{GDM}$ in previous pregnancies $(\mathrm{aOR}=4.30)$, and pregestational $\mathrm{DM}(\mathrm{PGDM})$ in the 3 months before this pregnancy $(\mathrm{aOR}=6.78)$. Polymorphisms of the $N K X 2.5$ gene at $\mathrm{rs} 11802669(\mathrm{C} / \mathrm{C}$ vs. T/T: $\mathrm{aOR}=4.97 ; \mathrm{C} / \mathrm{T}$ vs. $\mathrm{T} / \mathrm{T}: \mathrm{aOR}=2.15$ ) and $\mathrm{rs} 2277923(\mathrm{~T} / \mathrm{T}$ vs. $\mathrm{C} / \mathrm{C}, \mathrm{aOR}=1.74 ; \mathrm{T} / \mathrm{C}$ vs. $\mathrm{C} / \mathrm{C}, \mathrm{aOR}=1.61$ ) were significantly associated with the risk of CHD in offspring. In addition, significant interactions between maternal DM and NKX2.5 genetic variants at rs11802669 $(\mathrm{aOR}=8.12)$ and $\mathrm{rs} 2277923(\mathrm{aOR}=17.72)$ affecting the development of CHD were found. Conclusions. These results suggest that maternal DM, NKX2.5 genetic variants, and their interactions are significantly associated with the risk of CHD in offspring.

\section{Introduction}

Congenital heart disease (CHD) is one of the most common birth defects among newborns, accounting for a large proportion of infant mortality worldwide. As a rough estimate, approximately 8 infants in every 1000 are born with CHD [1]. The pathogenesis of $\mathrm{CHD}$, however, is very complicated and different from other congenital diseases, and its exact causes are largely undefinable [2].

Approximately $2 \%$ of $\mathrm{CHD}$ can be attributed to known environmental factors, of which maternal diabetes mellitus $(D M)$ is a well-accepted risk factor [3]. Gestational diabetes mellitus (GDM) poses significant risks of immediate and long-term health for the mother and foetus, affecting 3\%- 
$25 \%$ of pregnancies worldwide [4]. Studies have demonstrated that glycaemic control during pregnancy has a clear link to foetal malformations, and maternal DM appears to induce offspring malformation before the seventh week of gestation [5]. One hypothesis is that the abnormal glucose levels in maternal DM disrupt the expression of regulatory genes in the embryo, resulting in embryotoxic apoptotic cellular changes [6].

Over 40 genes have been implicated in the development of CHD [7]. Examples of CHD-causing mutations are those in $N K X 2.5$, a transcriptional regulator during early embryonic heart development $[8,9]$. Experiments have shown that NKX2.5 is essential for the formation and maturation of the heart as well as the conduction system. Its absence in mice results in embryonic lethality and arrested heart development [10]. In addition, more than 40 mutations of NKX2.5 have been found in CHD cases, which may reduce the transcriptional activity of NKX2.5 and affect cardiac development [11]. Several animal experiments have shown that NKX2.5 may be involved in the pathogenesis of embryonic congenital heart disease caused by gestational diabetes and that in a rat model, the expression of NKX2.5 decreased during heart development in foetuses of mothers with gestational diabetes [12-14].

Accordingly, we conducted a case-control study including 620 mothers of CHD patients and 620 mothers of healthy children, collecting mothers' information by questionnaire and detecting children's NKX2.5 variants with a MassARRAY system, to study the association of maternal DM, NKX2.5 variants and their interaction with CHD in offspring to provide a new direction for the prevention of CHD.

\section{Methods}

2.1. Recruitment of Study Participants. We conducted a casecontrol study to investigate the role of maternal DM and NKX2.5 SNPs in the aetiology of CHD in offspring. Recruitment was conducted by the Hunan Children's Hospital from November 2017 to December 2019. Children with CHD and their parents who were seen in this hospital were identified as the case group. All CHD patients were diagnosed using ultrasonography, and their diagnosis was confirmed by surgery. Children without any congenital malformation after a medical examination and their parents were identified as the control group. The study participants were recruited at 2 clinics from this hospital. The case group was recruited from the Department of Cardiothoracic Surgery, which provides diagnosis, treatment, surgery, and management for $\mathrm{CHD}$, and the control group was recruited from the Department of Child Healthcare after health counselling or a medical examination. The controls were selected from the same hospital during the same study period as the cases. This study was approved by the ethics committee of the Xiangya School of Public Health of Central South University, and written informed consent was obtained from all mothers. This study was registered in the Chinese Clinical Trial Registry Center (registration number: ChiCTR1800016635).
2.2. Inclusion Criteria. In this study, the exposures of interest were maternal DM and children's genetic variants of the NKX2.5 gene. DM was identified based on the following International Classification of Diseases and Related Health Problems, Tenth Revision (ICD-10) code: O24.4. Three types of maternal DM were included: gestational DM (GDM) during this pregnancy, GDM in previous pregnancies, and pregestational DM (PGDM) in the 3 months before this pregnancy. The outcomes of interest were CHD in the offspring, including seven subtypes: atrial septal defect (ASD), ventricular septal defect (VSD), atrioventricular septal defect (AVSD), patent ductus arteriosus (PDA), aortopulmonary septal defect (APSD), tetralogy of Fallot (TOF), and complete transposition of the great arteries (CTOGA). All CHD patients were diagnosed using ultrasonography, and their diagnosis was confirmed by surgery.

To reduce recall bias, mothers with children under 1 year old were recruited and asked to complete the same questionnaire in the same way by professionally trained investigators who were not informed in advance of the classification of the cases and controls. Additionally, this study was aimed at mothers of Han Chinese descent with singleton pregnancies. Eligible mothers needed to be able to complete the questionnaire and provide informed consent and blood samples. Nonsyndromic CHDs were of interest, and patients with other organ malformations or known abnormalities were excluded. Children without any congenital malformation after a medical examination served as the controls.

2.3. Information Collection. A standardized questionnaire was used to assess the history of maternal DM, including GDM during this pregnancy, GDM in previous pregnancies, and PGDM in the 3 months before this pregnancy. In addition, we consulted the Maternal and Child Health Manual and maternal medical records to further confirm the corresponding information on maternal DM history. In China, each pregnant woman is provided with a Maternal and Child Health Manual in which to record their basic demographic characteristics, behavioural habits, illnesses, and the results of various medical examinations during pregnancy. Another major exposure of interest in this study was the SNPs of the NKX2.5 gene at rs6882776, rs118026695, rs2277923, and rs703752, which are described below.

When evaluating the association of maternal DM and NKX2.5 SNPs with the risk of CHD in offspring, some other confounding factors needed to be considered. Therefore, we collected the following information about the mothers: (1) demographic characteristics, (2) abnormal pregnancy history, (3) family history, (4) personal medical history, (5) lifestyle and habits, (6) history of exposure to environmental hazardous substances, and (7) medical history during this pregnancy.

2.4. NKX2.5 SNP Sequencing. The genetic loci rs6882776, rs118026695, rs2277923, and rs703752 of the NKX2.5 gene, which have been widely studied previously, were selected as candidate loci for this study [15-17]. Three to five millilitres of peripheral venous blood from the children was used for genotyping. Blood samples were collected in EDTA-treated 
TABLE 1: Baseline characteristics comparison between control group and case group.

\begin{tabular}{|c|c|c|c|}
\hline Variables & Control group $(n=620)$ & Case group $(n=620)$ & Univariable analysis \\
\hline \multicolumn{4}{|l|}{ Demographic characteristics } \\
\hline Maternal age at this pregnancy (years) & $28.5 \pm 4.7$ & $28.0 \pm 5.4$ & \multirow{5}{*}{$\chi^{2}=13.755 ; P=0.003$} \\
\hline$\leq 24$ & $124(20.0 \%)$ & $176(28.4 \%)$ & \\
\hline $25-29$ & $261(42.1 \%)$ & $235(37.9 \%)$ & \\
\hline $30-34$ & $152(24.5 \%)$ & $122(19.7 \%)$ & \\
\hline$\geq 35$ & $83(13.4 \%)$ & $87(14.0 \%)$ & \\
\hline \multicolumn{4}{|l|}{ Education level } \\
\hline Less than primary or primary & $7(1.1 \%)$ & $87(14.0 \%)$ & \multirow{4}{*}{$Z=14.342 ; P \leq 0.001$} \\
\hline Junior high school & $117(18.9 \%)$ & $263(42.4 \%)$ & \\
\hline Senior middle school & $217(35.0 \%)$ & $167(26.9 \%)$ & \\
\hline College or above & $279(45.0 \%)$ & $103(16.6 \%)$ & \\
\hline \multicolumn{4}{|l|}{ Body mass index before this pregnancy } \\
\hline$<18.5$ & $156(25.8 \%)$ & $112(18.3 \%)$ & \multirow{3}{*}{$Z=1.625 ; P=0.104$} \\
\hline $18.5-23.99$ & $340(56.3 \%)$ & $404(65.9 \%)$ & \\
\hline$\geq 24$ & $108(17.9 \%)$ & $97(15.8 \%)$ & \\
\hline \multicolumn{4}{|c|}{ Family's annual income in the past 1 year (RMB) } \\
\hline$\leq 50,000$ & $179(28.9 \%)$ & $494(79.7 \%)$ & \multirow[t]{4}{*}{$Z=17.785 ; P \leq 0.001$} \\
\hline $60,000-100,000$ & $267(43.1 \%)$ & $92(14.8 \%)$ & \\
\hline $110,000-150,000$ & $57(9.2 \%)$ & $12(1.9 \%)$ & \\
\hline$\geq 160,000$ & $117(18.9 \%)$ & $22(3.5 \%)$ & \\
\hline \multicolumn{4}{|l|}{ Residence location } \\
\hline Rural areas & $342(55.2 \%)$ & $444(71.6 \%)$ & \multirow[t]{2}{*}{$\chi^{2}=36.153 ; P \leq 0.001$} \\
\hline Urban areas & $278(44.8 \%)$ & $176(28.4 \%)$ & \\
\hline \multicolumn{4}{|l|}{ Abnormal pregnancy history } \\
\hline \multicolumn{4}{|l|}{ Spontaneous abortion } \\
\hline No & $560(90.3 \%)$ & $545(87.9 \%)$ & \multirow[t]{2}{*}{$\chi^{2}=1.870 ; P=0.171$} \\
\hline Yes & $60(9.7 \%)$ & $75(12.1 \%)$ & \\
\hline \multicolumn{4}{|l|}{ Induced abortion or labor } \\
\hline No & $428(69.0 \%)$ & $363(58.5 \%)$ & \multirow[t]{2}{*}{$\chi^{2}=14.751 ; P \leq 0.001$} \\
\hline Yes & $192(31.0 \%)$ & $257(41.5 \%)$ & \\
\hline \multicolumn{4}{|l|}{ Fetal death or stillbirth } \\
\hline No & $618(99.7 \%)$ & $584(94.2 \%)$ & \multirow[t]{2}{*}{$\chi^{2}=31.383 ; P \leq 0.001$} \\
\hline Yes & $2(0.3 \%)$ & $36(5.8 \%)$ & \\
\hline \multicolumn{4}{|l|}{ Premature delivery } \\
\hline No & $614(99.0 \%)$ & $603(97.3 \%)$ & \multirow[t]{2}{*}{$\chi^{2}=5.360 ; P=0.021$} \\
\hline Yes & $6(1.0 \%)$ & $17(2.7 \%)$ & \\
\hline \multicolumn{4}{|l|}{ Low birth weight } \\
\hline No & $617(99.5 \%)$ & $603(97.3 \%)$ & \multirow[t]{2}{*}{$\chi^{2}=9.961 ; P=0.002$} \\
\hline Yes & $3(0.5 \%)$ & $17(2.7 \%)$ & \\
\hline \multicolumn{4}{|l|}{ Neonatal death } \\
\hline No & $620(100.0 \%)$ & $603(97.3 \%)$ & \multirow[t]{2}{*}{$\chi^{2}=17.236 ; P \leq 0.001$} \\
\hline Yes & $0(0.0 \%)$ & $17(2.7 \%)$ & \\
\hline Embryo damage & & & \\
\hline No & $610(98.4 \%)$ & $604(97.4 \%)$ & $\chi^{2}=1.414 ; P=0.234$ \\
\hline Yes & $10(1.6 \%)$ & $16(2.6 \%)$ & \\
\hline Hypertension of pregnancy & & & \\
\hline No & $611(98.5 \%)$ & $577(93.1 \%)$ & $\chi^{2}=23.204 ; P \leq 0.001$ \\
\hline
\end{tabular}


TABle 1: Continued.

\begin{tabular}{|c|c|c|c|}
\hline Variables & Control group $(n=620)$ & Case group $(n=620)$ & Univariable analysis \\
\hline Yes & $9(1.5 \%)$ & $43(6.9 \%)$ & \\
\hline \multicolumn{4}{|c|}{ Placenta previa } \\
\hline No & $615(99.2 \%)$ & $613(98.9 \%)$ & \multirow[t]{2}{*}{$\chi^{2}=0.337 ; P=0.562$} \\
\hline Yes & $5(0.8 \%)$ & $7(1.1 \%)$ & \\
\hline \multicolumn{4}{|c|}{ Placental abruption } \\
\hline No & $620(100.0 \%)$ & $620(100.0 \%)$ & \\
\hline Yes & $0(0.0 \%)$ & $0(0.0 \%)$ & \\
\hline \multicolumn{4}{|c|}{ Premature rupture of membranes } \\
\hline No & $620(100.0 \%)$ & $615(99.2 \%)$ & \multirow{2}{*}{$P=0.062$ (Fisher's exact test) } \\
\hline Yes & $0(0.0 \%)$ & $0.8 \%$ & \\
\hline \multicolumn{4}{|c|}{ Anemia during pregnancy } \\
\hline No & $598(96.5 \%)$ & $554(89.4 \%)$ & \multirow[t]{2}{*}{$\chi^{2}=23.681 ; P \leq 0.001$} \\
\hline Yes & $22(3.5 \%)$ & $66(10.6 \%)$ & \\
\hline \multicolumn{4}{|c|}{ Family history } \\
\hline \multicolumn{4}{|c|}{ Consanguineous marriages } \\
\hline No & $617(99.5 \%)$ & $599(96.6 \%)$ & \multirow[t]{2}{*}{$\chi^{2}=13.766 ; P \leq 0.001$} \\
\hline Yes & $3(0.5 \%)$ & $21(3.4 \%)$ & \\
\hline \multicolumn{4}{|c|}{ Congenital malformations } \\
\hline No & $615(99.2 \%)$ & $584(94.2 \%)$ & \multirow{2}{*}{$\chi^{2}=24.241 ; P \leq 0.001$} \\
\hline Yes & $5(0.8 \%)$ & $36(5.8 \%)$ & \\
\hline \multicolumn{4}{|c|}{ Personal medical history } \\
\hline \multicolumn{4}{|c|}{ Personal history of congenital malformations } \\
\hline No & $617(99.5 \%)$ & $611(98.5 \%)$ & \multirow{2}{*}{$\chi^{2}=3.029 ; P=0.082$} \\
\hline Yes & $3(0.5 \%)$ & $9(1.5 \%)$ & \\
\hline \multicolumn{4}{|c|}{ Cold history in the 3 months before this pregnancy } \\
\hline No & $548(88.4 \%)$ & $499(80.5 \%)$ & \multirow[t]{2}{*}{$\chi^{2}=14.734 ; P \leq 0.001$} \\
\hline Yes & $72(11.6 \%)$ & $121(19.5 \%)$ & \\
\hline \multicolumn{4}{|c|}{ Fever history in the 3 months before this pregnancy } \\
\hline No & $608(98.1 \%)$ & $569(91.8 \%)$ & \multirow[t]{2}{*}{$\chi^{2}=25.435 ; P \leq 0.001$} \\
\hline Yes & $12(1.9 \%)$ & $51(8.2 \%)$ & \\
\hline \multicolumn{4}{|c|}{ Cold history during this pregnancy } \\
\hline No & $488(78.7 \%)$ & $413(66.6 \%)$ & \multirow[t]{2}{*}{$\chi^{2}=22.836 ; P \leq 0.001$} \\
\hline Yes & $132(21.3 \%)$ & $207(33.4 \%)$ & \\
\hline \multicolumn{4}{|c|}{ Fever history during this pregnancy } \\
\hline No & $601(96.9 \%)$ & $561(90.5 \%)$ & \multirow[t]{2}{*}{$\chi^{2}=21.890 ; P \leq 0.001$} \\
\hline Yes & $19(3.1 \%)$ & $59(9.5 \%)$ & \\
\hline Lifestyle ar & & & \\
\hline History of & ore this pregnancy & & \\
\hline No & $607(97.9 \%)$ & $584(94.2 \%)$ & $\chi^{2}=11.240 ; P=0.001$ \\
\hline Yes & $13(2.1 \%)$ & $36(5.8 \%)$ & \\
\hline History of & efore this pregnancy & & \\
\hline No & $393(63.4 \%)$ & $293(47.3 \%)$ & $\chi^{2}=32.628 ; P \leq 0.001$ \\
\hline Yes & $227(36.6 \%)$ & $327(52.7 \%)$ & \\
\hline Drinking $\mathrm{h}$ & regnancy & & \\
\hline No & $577(93.1 \%)$ & $539(86.9 \%)$ & $\chi^{2}=12.939 ; P \leq 0.001$ \\
\hline Yes & $43(6.9 \%)$ & $81(13.1 \%)$ & \\
\hline History of & this pregnancy & & \\
\hline
\end{tabular}


TABLe 1: Continued.

\begin{tabular}{cc}
\hline Variables & Control group $(n=620)$ \\
\hline No & $503(81.1 \%)$ \\
Yes & $117(18.9 \%)$ \\
History of drinking coffee in the 3 months before this pregnancy \\
No & $592(95.5 \%)$ \\
Yes & $28(4.5 \%)$
\end{tabular}

History of chewing betel nut in the 3 months before this pregnancy

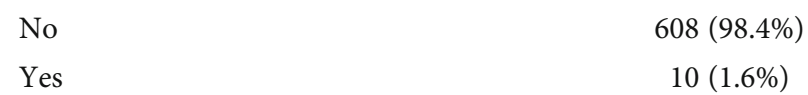

\begin{tabular}{|c|c|c|}
\hline 620) & Case group $(n=620)$ & Univariable analysis \\
\hline & $542(87.4 \%)$ & $\chi^{2}=9.256 ; P=0.002$ \\
\hline & $78(12.6 \%)$ & \\
\hline
\end{tabular}

Frequency of cosmetics use in the 3 months before this pregnancy

\begin{tabular}{|c|c|c|c|}
\hline Never & $360(58.1 \%)$ & $293(47.3 \%)$ & $Z=4.993 ; P \leq 0.001$ \\
\hline Sometime & $174(28.1 \%)$ & $150(24.2 \%)$ & \\
\hline Often & $40(6.5 \%)$ & $105(16.9 \%)$ & \\
\hline Every day & $46(7.4 \%)$ & $72(11.6 \%)$ & \\
\hline \multicolumn{4}{|c|}{ id you keep pets in the 3 months before this pregnancy? } \\
\hline No & $573(92.4 \%)$ & $537(86.6 \%)$ & $\chi^{2}=11.137 ; P=0.001$ \\
\hline Yes & $47(7.6 \%)$ & $83(13.4 \%)$ & \\
\hline \multicolumn{4}{|c|}{ id you often dye or perm your hair in the 3 months before this pregnancy? } \\
\hline No & $584(94.2 \%)$ & $547(88.2 \%)$ & $\chi^{2}=13.770 ; P \leq 0.001$ \\
\hline Yes & $36(5.8 \%)$ & $73(11.8 \%)$ & \\
\hline
\end{tabular}

Exposure history to environmental hazardous substance

Was there a factory near place of residence that discharges environmentally harmful substances?
No
$574(92.6 \%)$
$503(81.1 \%)$
Yes
$46(7.4 \%)$
$117(18.9 \%)$

$\chi^{2}=35.607 ; P \leq 0.001$

Was there a traffic road or a noisy factory near where you live (noise exposure)?

$\begin{array}{lccc}\text { No } & 506(81.6 \%) & 446(71.9 \%) & \chi^{2}=16.282 ; P \leq 0.001 \\ \text { Yes } & 114(18.4 \%) & 174(28.1 \%) & \\ \text { Was your house newly renovated in the } 3 \text { months before this pregnancy? } & 572(92.3 \%) & \chi^{2}=0.269 ; P=0.604 \\ \text { No } & 567(91.5 \%) & 48(7.7 \%) & \end{array}$

Medicine history in this pregnancy

Folate

\begin{tabular}{|c|c|c|c|}
\hline Yes & $577(93.1 \%)$ & $526(84.8 \%)$ & $\chi^{2}=21.344 ; P \leq 0.001$ \\
\hline No & $43(6.9 \%)$ & $94(15.2 \%)$ & \\
\hline \multicolumn{4}{|c|}{ Macrolide antibiotics } \\
\hline No & $603(97.3 \%)$ & $569(91.8 \%)$ & \multirow[t]{2}{*}{$\chi^{2}=17.986 ; P \leq 0.001$} \\
\hline Yes & $17(2.7 \%)$ & $51(8.2 \%)$ & \\
\hline \multicolumn{4}{|c|}{ Antidepressants } \\
\hline No & $586(94.5 \%)$ & $551(88.9 \%)$ & \multirow[t]{2}{*}{$\chi^{2}=12.971 ; P \leq 0.001$} \\
\hline Yes & $34(5.5 \%)$ & $69(11.1 \%)$ & \\
\hline \multicolumn{4}{|c|}{ etal-prevention drugs } \\
\hline No & $539(86.9 \%)$ & $487(78.5 \%)$ & \multirow[t]{2}{*}{$\chi^{2}=15.271 ; P \leq 0.001$} \\
\hline Yes & $81(13.1 \%)$ & $133(21.5 \%)$ & \\
\hline
\end{tabular}

(ethylenediamine tetraacetic acid) anticoagulant tubes and then immediately centrifuged into plasma and white blood cells. White blood cells were separated and stored at $-80^{\circ} \mathrm{C}$ until genotyping was performed. DNA was extracted from blood cells by the QIAamp DNA Mini Kit (Qiagen, Valencia, CA, USA) according to the manufacturer's standard protocol and dissolved in sterile TBE (Tris-borate-EDTA) buffer. The concentration and purity of the DNA solution were detected 
TABLE 2: Univariate analysis of maternal DM and offspring CHD.

\begin{tabular}{|c|c|c|c|c|}
\hline Maternal DM & Control group $(n=620)$ & Case group $(n=620)$ & Univariable analysis & Unadjusted OR (95\% CI) \\
\hline \multicolumn{5}{|c|}{ GDM during this pregnancy } \\
\hline No & $592(95.5 \%)$ & $552(89.0 \%)$ & \multirow{2}{*}{$\chi^{2}=18.065 ; P \leq 0.001$} & 1 \\
\hline Yes & $28(4.5 \%)$ & $68(11.0 \%)$ & & $2.61(1.65-4.11) *$ \\
\hline \multicolumn{5}{|c|}{ GDM during previous pregnancy experience } \\
\hline No & $595(96.0 \%)$ & $550(88.7 \%)$ & \multirow{2}{*}{$\chi^{2}=23.084 ; P \leq 0.001$} & 1 \\
\hline Yes & $25(4.0 \%)$ & $70(11.3 \%)$ & & $3.03(1.89-4.85)^{*}$ \\
\hline \multicolumn{5}{|c|}{ PGDM in the 3 months before this pregnancy } \\
\hline No & $603(97.3 \%)$ & $557(89.8 \%)$ & \multirow{2}{*}{$\chi^{2}=28.274 ; P \leq 0.001$} & 1 \\
\hline Yes & $17(2.7 \%)$ & $63(10.2 \%)$ & & $4.01(2.32-6.94)^{*}$ \\
\hline
\end{tabular}

DM: diabetes mellitus; CHD: congenital heart disease; GDM: gestational diabetes mellitus; PGDM: pregestational diabetes mellitus; OR: odds ratio; CI: confidence interval. *Statistically significant $(a=0.05)$.

TABLE 3: Multivariate analysis of maternal DM and offspring CHD.

\begin{tabular}{lccccc}
\hline Maternal DM & B & S.E & Wals & $P$ value & Adjusted OR (95\% CI)* \\
\hline GDM during this pregnancy (yes vs. no) & 1.609 & 0.340 & 22.326 & 0.001 & $4.98(2.56-9.74)$ \\
GDM in previous pregnancy experiences (yes vs. no) & 1.458 & 0.334 & 19.117 & 0.001 & $4.30(2.24-8.27)$ \\
PGDM in the 3 months before this pregnancy (yes vs. no) & 1.914 & 0.385 & 24.676 & 0.001 & $6.78(3.19-14.43)$ \\
\hline
\end{tabular}

DM: diabetes mellitus; CHD: congenital heart disease; GDM: gestational diabetes mellitus; PGDM: pregestational diabetes mellitus; OR: odds ratio; CI: confidence interval. * Adjusted for factors with statistical differences in Table 1.

by ultraviolet spectrophotometry to ensure that the DNA was eligible as a template for polymerase chain reaction (PCR).

Primer designs, amplification conditions, and expected product sizes for NKX2.5 have been described by previous studies [15-17]. The polymorphisms of the NKX2.5 gene at rs6882776, rs118026695, rs2277923, and rs703752 were tested using a matrix-assisted laser desorption and ionization time-of-flight mass spectrometry MassARRAY system (Agena iPLEXassay, San Diego, CA, USA). The error rate for genotyping was less than $5 \%$. The experimenters who performed the genotyping were not informed in advance of the status of the control or case groups. Each sample was retyped and double-checked to ensure the reliability of the experiments.

For rs6882776, three genotypes, including the homozygous wild-type G/G, the heterozygous variant T/A, and the homozygous variant A/A, were identified. For rs118026695, three genotypes were identified: the homozygous wild-type $\mathrm{T} / \mathrm{T}$, the heterozygous variant $\mathrm{C} / \mathrm{T}$, and the homozygous variant C/C. For rs2277923, three genotypes were identified: the homozygous wild-type $\mathrm{T} / \mathrm{T}$, the heterozygous variant $\mathrm{T} / \mathrm{C}$, and the homozygous variant C/C. For rs703752, three genotypes were identified: the homozygous wild-type $\mathrm{C} / \mathrm{C}$, the heterozygous variant $\mathrm{C} / \mathrm{A}$, and the homozygous variant $\mathrm{A} / \mathrm{A}$.

2.5. Statistical Analysis. Means and standard deviations were reported for normally distributed continuous variables. For continuous variables that did not seem normally distributed and categorical variables, quartiles (\%) were reported. In the univariate analysis, the Pearson chi-squared test or Fisher's exact test was used to compare categorical variable data; the Wilcoxon rank sum test was used for nonnormally distributed continuous variables.

NKX2.5 SNPs were analysed for deviations from HardyWeinberg equilibrium (HWE). The correlation analysis for CHD and maternal DM or NKX2.5 SNPs was performed by univariate and multivariate logistic regression analysis, and odds ratios (ORs) and their 95\% confidence intervals (CIs) were used to assess the level of association. The ORs were adjusted (aORs) using the factors with $P$ values less than 0.05 in Table 1 . We used logistic regression and controlled for potential confounding factors to examine the main effects and interactive effects of the gene-environment interaction of the NKX2.5 gene and maternal DM on the risk of CHD in offspring.

In the logistic regression model, the confounding factors, maternal DM, and NKX2.5 SNPs were set as independent variables (covariates), and the effects were expressed as ORs with 95\% CIs. Offspring diagnostic results were set as dependent variables (binary outcomes). Models of the geneenvironment interactions and their implications referred to the method described by Wallace [17]. The interaction coefficient $(\gamma)$ was calculated as a function of the regression coefficient $(\beta)$ from the logistic regression analysis (e.g., $\gamma 1=\beta \mathrm{e} * \mathrm{~g} / \beta \mathrm{e}$ and $\gamma 2=\beta \mathrm{e} * \mathrm{~g} / \beta \mathrm{g}$ for gene-environment interaction) and was used to evaluate the interaction [18]. When all $\gamma$ values were greater than 1 , there was a positive interaction; when all $\gamma$ values were less than 1 , there was a negative interaction; and when the $\gamma$ values were equal to 1 , there was no interaction.

In this study, we examined the risk of total CHD instead of the risk of specific subtypes due to the limited sample size. 
TABLE 4: Univariate analysis of NKX2.5 gene polymorphism and CHD.

\begin{tabular}{|c|c|c|c|c|}
\hline SNP of NKX2.5 gene & Control group $(n=620)$ & Case group $(n=620)$ & Univariate analysis & Unadjusted OR (95\% CI) \\
\hline Genotype at rs6882776 & & & & $0.98(0.83-1.16)$ \\
\hline $\mathrm{A} / \mathrm{A}$ & $216(34.8 \%)$ & $209(33.7 \%)$ & & 1 \\
\hline $\mathrm{G} / \mathrm{A}$ & $308(49.7 \%)$ & $328(52.9 \%)$ & $\chi^{2}=1.688 ; P=0.430$ & $1.10(0.86-1.41)$ \\
\hline $\mathrm{G} / \mathrm{G}$ & $96(15.5 \%)$ & $83(13.4 \%)$ & & $0.89(0.63-1.27)$ \\
\hline \multicolumn{5}{|c|}{ Recessive model at rs6882776 } \\
\hline $\mathrm{A} / \mathrm{A}$ & $216(34.8 \%)$ & $209(33.7 \%)$ & $\chi^{2}=0.175 ; P=0.675$ & 1 \\
\hline $\mathrm{G} / \mathrm{A}+\mathrm{G} / \mathrm{G}$ & $404(65.2 \%)$ & $411(66.3 \%)$ & & $1.05(0.83-1.33)$ \\
\hline \multicolumn{5}{|c|}{ Dominant model at rs6882776 } \\
\hline $\mathrm{A} / \mathrm{A}+\mathrm{G} / \mathrm{A}$ & $524(84.5 \%)$ & $537(86.6 \%)$ & $\chi^{2}=1.103 ; P=0.294$ & 1 \\
\hline $\mathrm{G} / \mathrm{G}$ & $96(15.5 \%)$ & $83(13.4 \%)$ & & $0.84(0.61-1.16)$ \\
\hline \multicolumn{5}{|l|}{ Allele at rs6882776 } \\
\hline A & $740(59.7 \%)$ & $746(60.2 \%)$ & \multirow{2}{*}{$\chi^{2}=0.060 ; P=0.806$} & 1 \\
\hline G & $500(40.3 \%)$ & $494(39.8 \%)$ & & $0.98(0.84-1.15)$ \\
\hline \multicolumn{4}{|l|}{ Genotype at rs118026695 } & $1.83(1.42-2.36)^{*}$ \\
\hline $\mathrm{T} / \mathrm{T}$ & $510(82.3 \%)$ & $443(71.5 \%)$ & \multirow{3}{*}{$\chi^{2}=22.949 ; P \leq 0.001$} & 1 \\
\hline $\mathrm{C} / \mathrm{T}$ & $107(17.3 \%)$ & $164(26.5 \%)$ & & $1.77(1.34-2.32)^{*}$ \\
\hline $\mathrm{C} / \mathrm{C}$ & $3(0.5 \%)$ & $13(2.1 \%)$ & & $4.99(1.41-17.62)^{*}$ \\
\hline \multicolumn{5}{|c|}{ Recessive model at rs118026695 } \\
\hline $\mathrm{T} / \mathrm{T}$ & $510(82.3 \%)$ & $443(71.5 \%)$ & \multirow[t]{2}{*}{$\chi^{2}=20.352 ; P \leq 0.001$} & 1 \\
\hline $\mathrm{C} / \mathrm{T}+\mathrm{C} / \mathrm{C}$ & $110(17.7 \%)$ & $177(28.5 \%)$ & & $1.85(1.41-2.43)^{*}$ \\
\hline \multicolumn{5}{|c|}{ Dominant model at rs118026695 } \\
\hline $\mathrm{T} / \mathrm{T}+\mathrm{C} / \mathrm{T}$ & $617(99.5 \%)$ & $607(97.9 \%)$ & \multirow[t]{2}{*}{$\chi^{2}=6.332 ; P=0.012$} & 1 \\
\hline $\mathrm{C} / \mathrm{C}$ & $3(0.5 \%)$ & $13(2.1 \%)$ & & $4.41(1.25-15.53)^{*}$ \\
\hline \multicolumn{5}{|l|}{ Allele at rs118026695 } \\
\hline $\mathrm{T}$ & $1127(90.9 \%)$ & $1050(84.7 \%)$ & \multirow{2}{*}{$\chi^{2}=22.291 ; P \leq 0.001$} & 1 \\
\hline $\mathrm{C}$ & $113(9.1 \%)$ & $190(15.3 \%)$ & & $1.81(1.41-2.31)^{*}$ \\
\hline \multicolumn{3}{|l|}{ Genotype at rs2277923 } & & $1.38(1.17-1.62)^{*}$ \\
\hline $\mathrm{C} / \mathrm{C}$ & $291(46.9 \%)$ & $217(35.0 \%)$ & \multirow{3}{*}{$\chi^{2}=18.268 ; P \leq 0.001$} & 1 \\
\hline $\mathrm{T} / \mathrm{C}$ & $254(41.0 \%)$ & $310(50.0 \%)$ & & $1.64(1.29-2.08)^{*}$ \\
\hline $\mathrm{T} / \mathrm{T}$ & $75(12.1 \%)$ & $93(15.0 \%)$ & & $1.66(1.17-2.36)^{*}$ \\
\hline \multicolumn{5}{|c|}{ Recessive model at rs2277923 } \\
\hline $\mathrm{C} / \mathrm{C}$ & $291(46.9 \%)$ & $217(35.0 \%)$ & \multirow[t]{2}{*}{$\chi^{2}=18.260 ; P \leq 0.001$} & 1 \\
\hline $\mathrm{T} / \mathrm{C}+\mathrm{T} / \mathrm{T}$ & $329(53.1 \%)$ & $403(65.0 \%)$ & & $1.64(1.31-2.06)^{*}$ \\
\hline \multicolumn{5}{|c|}{ Dominant model at rs2277923 } \\
\hline $\mathrm{C} / \mathrm{C}+\mathrm{T} / \mathrm{C}$ & $545(87.9 \%)$ & $527(85.0 \%)$ & \multirow[t]{2}{*}{$\chi^{2}=2.231 ; P=0.135$} & 1 \\
\hline $\mathrm{T} / \mathrm{T}$ & $75(12.1 \%)$ & $93(15.0 \%)$ & & $1.28(0.93-1.78)$ \\
\hline \multicolumn{5}{|l|}{ Allele at rs2277923 } \\
\hline $\mathrm{C}$ & $836(67.4 \%)$ & $744(60.0 \%)$ & \multirow{2}{*}{$\chi^{2}=14.761 ; P \leq 0.001$} & 1 \\
\hline $\mathrm{T}$ & $404(32.6 \%)$ & $496(40.0 \%)$ & & $1.38(1.17-1.63)^{*}$ \\
\hline \multicolumn{3}{|l|}{ Genotype at rs703752 } & \multirow{4}{*}{$P=0.009$ (Fisher's exact test) } & $1.66(1.20-2.29)^{*}$ \\
\hline $\mathrm{A} / \mathrm{A}$ & $7(1.1 \%)$ & $2(0.3 \%)$ & & 1 \\
\hline $\mathrm{C} / \mathrm{A}$ & $86(13.9 \%)$ & $57(9.2 \%)$ & & $2.32(0.47-11.57)$ \\
\hline $\mathrm{C} / \mathrm{C}$ & $527(85.0 \%)$ & $561(90.5 \%)$ & & $3.73(0.77-18.02)$ \\
\hline \multicolumn{5}{|c|}{ Recessive model at rs703752 } \\
\hline $\mathrm{A} / \mathrm{A}+\mathrm{C} / \mathrm{A}$ & $93(15.0 \%)$ & $59(9.5 \%)$ & $\chi^{2}=8.668 ; P=0.003$ & 1 \\
\hline $\mathrm{C} / \mathrm{C}$ & $527(85.0 \%)$ & $561(90.5 \%)$ & & $1.68(1.19-2.38)^{*}$ \\
\hline
\end{tabular}


Table 4: Continued.

\begin{tabular}{lcccc}
\hline SNP of NKX2.5 gene & Control group $(n=620)$ & Case group $(n=620)$ & Univariate analysis & Unadjusted OR (95\% CI) \\
\hline $\begin{array}{l}\text { Dominant model at rs703752 } \\
\text { A/A }\end{array}$ & $7(1.1 \%)$ & $2(0.3 \%)$ & & \\
C/A+C/C & $613(98.9 \%)$ & $618(99.7 \%)$ & $P=0.178$ (Fisher's exact test) & $3.53(0.73-17.05)$ \\
Allele at rs703752 & $100(8.1 \%)$ & $61(4.9 \%)$ & $\chi^{2}=10.103 ; P=0.001$ & 1 \\
A & $1140(91.9 \%)$ & $1179(95.1 \%)$ & & $1.70(1.22-2.36)^{*}$ \\
C & & & & 1 \\
\hline
\end{tabular}

OR: odds ratio; CI: confidence interval. *Statistically significant $(a=0.05)$.

All data were analysed using SPSS (IBM SPSS Statistics for Macintosh, Version 26.0, Armonk, NY: IBM Corp). $P<$ 0.05 was considered statistically significant.

\section{Results}

3.1. Comparison of Baseline Characteristics. We analysed seven aspects of the 1240 questionnaires (620 control groups and 620 case groups) (Table 1$)$. The pregnancy age $(P=0.003$ ) , educational level $(P \leq 0.001)$, and family annual income $(P \leq 0.001)$ of women in the case group were significantly lower than those in the control group. However, there was no significant difference in BMI $(P=0.104)$. Moreover, the incidences of history of abnormal pregnancy (except for spontaneous abortion, embryo damage, and placenta previa), familial congenital malformations, personal medical history (except for history of congenital malformation), history of exposure to environmental hazardous substances (except for house renovation), and medication history during this pregnancy (except for folic acid) were significantly higher in the case group than in the control group. There were also significant differences in lifestyle between the two groups. The factors with $P$ values less than 0.05 were included in the follow-up multivariate analysis.

3.2. Maternal DM Increases the Risk of Offspring CHD. During this pregnancy, $10.2 \%$ of women had PGDM, and $11.0 \%$ had GDM in the case group, both of which were significantly higher than the respective percentages of women in the control group $(P<0.001)$ (Table 2$)$. There were also more women with GDM during previous pregnancies in the case group $(P \leq 0.001)$. The unadjusted ORs for these three types of maternal DM were 2.61, 3.03, and 4.01, respectively, which demonstrated that if the mother had a history of DM, there was a higher risk for their offspring to develop CHD. Next, the relationship between maternal DM and offspring CHD was analysed by multivariate analysis (Table 3). Maternal DM was classified into 3 types, including GDM during this pregnancy, GDM in previous pregnancies, and PGDM in the 3 months before this pregnancy, and the risk factors in Table 1, such as age, educational level, and medical history, were adjusted in the analysis of these three types. There was a significant correlation between maternal DM and offspring CHD $(P \leq 0.001)$, and maternal DM increased the risk of offspring $\mathrm{CHD}(\mathrm{aOR}=4.98,4.30,6.78$, respectively).
3.3. NKX2.5 Variation Increases the Risk of CHD in Offspring. Univariate analysis showed that there were associations between $\mathrm{CHD}$ and the genotype or allele frequencies of any polymorphism of rs118026695, rs2277923, and rs703752 in NKX2.5 (Table 4). Next, we performed multivariate analysis (Table 5). The homozygous genotypes with a larger number of control groups were used as the control genotype. The confounding factors in Table 1 were adjusted in the analysis. Mutations of rs118026695 and rs2277923 were demonstrated to be associated with $\mathrm{CHD}$.

$\mathrm{T} / \mathrm{T}, \mathrm{C} / \mathrm{T}$, and $\mathrm{C} / \mathrm{C}$ genotypes were detected at rs118026695, and their frequency distributions were significantly different between the control and case groups $(P \leq 0.001)$. The logistic regression analysis revealed that $\mathrm{C} / \mathrm{T}(P \leq 0.001, \mathrm{aOR}=2.15,95 \% \mathrm{CI})$ and $\mathrm{C} / \mathrm{C}(P=0.023$, $\mathrm{aOR}=4.97,95 \% \mathrm{CI}$ ) were positively correlated with $\mathrm{CHD}$. The frequency distribution of 2 alleles $(C, T)$ also showed a significant difference between the control and case groups $(P \leq 0.001)$, and the logistic regression analysis showed that the $\mathrm{C}$ allele was positively correlated with $\mathrm{CHD}(P \leq 0.001$, $\mathrm{OR}=1.81,95 \% \mathrm{CI}$ ).

$\mathrm{C} / \mathrm{C}, \mathrm{T} / \mathrm{C}$, and $\mathrm{T} / \mathrm{T}$ genotypes were detected at $\mathrm{rs} 2277923$, and their frequency distributions were significantly different between the control and case groups $(P \leq 0.001)$. The logistic regression analysis revealed that $\mathrm{T} / \mathrm{C}(P=0.004, \mathrm{aOR}=1.61$, $95 \% \mathrm{CI})$ and $\mathrm{T} / \mathrm{T}(P=0.021, \mathrm{aOR}=1.74,95 \% \mathrm{CI})$ were positively correlated with $\mathrm{CHD}$. The frequency distribution of 2 alleles $(\mathrm{C}, \mathrm{T})$ also showed a significant difference between the control and case groups $(P \leq 0.001)$, and the logistic regression analysis showed that the $\mathrm{T}$ allele was positively correlated with $\mathrm{CHD}(P \leq 0.001, \mathrm{OR}=1.38,95 \% \mathrm{CI})$.

3.4. Analysis of the Interaction of Maternal DM and NKX2.5 in the Development of CHD in Offspring. Based on the above results, three types of maternal DM and the NKX2.5 SNPs at rs11802669 and rs2277923 were chosen to undergo further analysis (Table 6). We analysed their interaction and found that the interactions between maternal GDM during this pregnancy and $\mathrm{C} / \mathrm{T}$ at $\mathrm{rs} 11802669(P=0.008, \mathrm{aOR}=8.12$, $95 \% \mathrm{CI})$ or $\mathrm{T} / \mathrm{C}$ at $\mathrm{rs} 2277923(P \leq 0.001, \mathrm{aOR}=17.72,95 \%$ $\mathrm{CI})$ increased the risk of $\mathrm{CHD}$ in offspring.

\section{Discussion}

Cardiac development is a complicated process involving the dual roles of genes and the environment. A classic example 
TABLE 5: Multivariate analysis of NKX2.5 gene polymorphism and CHD.

\begin{tabular}{|c|c|c|c|c|c|}
\hline NKX2.5 gene & B & S.E & Wals & $\begin{array}{c}P \\
\text { value }\end{array}$ & $\begin{array}{l}\text { Adjusted OR }(95 \% \\
\text { CI })^{*}\end{array}$ \\
\hline \multicolumn{6}{|c|}{$\begin{array}{l}\text { Genotype at rs6882776 } \\
(\text { control genotype }=\mathrm{A} / \mathrm{A})\end{array}$} \\
\hline $\mathrm{G} / \mathrm{A}$ & 0.082 & 0.169 & 0.238 & 0.626 & $1.09(0.78-1.51)$ \\
\hline G/G & 0.018 & 0.239 & 0.006 & 0.940 & $1.02(0.64-1.63)$ \\
\hline $\begin{array}{l}\text { Additive } \\
\text { model }\end{array}$ & 0.026 & 0.114 & 0.050 & 0.822 & $1.03(0.82-1.28)$ \\
\hline $\begin{array}{l}\text { Recessive } \\
\text { model }\end{array}$ & 0.068 & 0.161 & 0.179 & 0.673 & $1.07(0.78-1.47)$ \\
\hline $\begin{array}{l}\text { Dominant } \\
\text { model }\end{array}$ & -0.031 & 0.217 & 0.020 & 0.886 & $0.97(0.63-1.48)$ \\
\hline \multicolumn{6}{|c|}{$\begin{array}{l}\text { Genotype at rs118026695 } \\
(\text { control genotype }=\mathrm{T} / \mathrm{T})\end{array}$} \\
\hline $\mathrm{C} / \mathrm{T}$ & 0.766 & 0.196 & 15.297 & 0.001 & $2.15(1.47-3.16)$ \\
\hline $\mathrm{C} / \mathrm{C}$ & 1.603 & 0.707 & 5.147 & 0.023 & $4.97(1.24-19.86)$ \\
\hline $\begin{array}{l}\text { Additive } \\
\text { model }\end{array}$ & 0.774 & 0.175 & 19.521 & 0.001 & $2.17(1.54-3.06)$ \\
\hline $\begin{array}{l}\text { Recessive } \\
\text { model }\end{array}$ & 0.821 & 0.191 & 18.546 & 0.001 & $2.27(1.56-3.30)$ \\
\hline $\begin{array}{l}\text { Dominant } \\
\text { model }\end{array}$ & 1.450 & 0.704 & 4.241 & 0.039 & $4.26(1.07-16.95)$ \\
\hline \multicolumn{6}{|c|}{$\begin{array}{l}\text { Genotype at rs2277923 } \\
(\text { control genotype }=\mathrm{C} / \mathrm{C})\end{array}$} \\
\hline $\mathrm{T} / \mathrm{C}$ & 0.477 & 0.167 & 8.127 & 0.004 & $1.61(1.16-2.24)$ \\
\hline $\mathrm{T} / \mathrm{T}$ & 0.555 & 0.240 & 5.352 & 0.021 & $1.74(1.09-2.79)$ \\
\hline $\begin{array}{l}\text { Additive } \\
\text { model }\end{array}$ & 0.328 & 0.113 & 8.478 & 0.004 & $1.39(1.11-1.73)$ \\
\hline $\begin{array}{l}\text { Recessive } \\
\text { model }\end{array}$ & 0.496 & 0.158 & 9.840 & 0.002 & $1.64(1.20-2.24)$ \\
\hline $\begin{array}{l}\text { Dominant } \\
\text { model }\end{array}$ & 0.302 & 0.222 & 1.842 & 0.175 & $1.35(0.88-2.09)$ \\
\hline \multicolumn{6}{|c|}{$\begin{array}{l}\text { Genotype at rs703752 } \\
(\text { control genotype = A/A) }\end{array}$} \\
\hline $\mathrm{C} / \mathrm{A}$ & 0.467 & 0.970 & 0.232 & 0.630 & $1.60(0.24-10.68)$ \\
\hline $\mathrm{C} / \mathrm{C}$ & 0.893 & 0.947 & 0.889 & 0.346 & $2.44(0.38-15.63)$ \\
\hline $\begin{array}{l}\text { Additive } \\
\text { model }\end{array}$ & 0.430 & 0.212 & 4.098 & 0.043 & $1.54(1.01-2.33)$ \\
\hline $\begin{array}{l}\text { Recessive } \\
\text { model }\end{array}$ & 0.452 & 0.229 & 3.908 & 0.048 & $1.57(1.00-2.46)$ \\
\hline $\begin{array}{l}\text { Dominant } \\
\text { model }\end{array}$ & 0.847 & 0.946 & 0.802 & 0.371 & $2.33(0.37-14.90)$ \\
\hline
\end{tabular}

OR: odds ratio; CI: confidence interval; SNP: single-nucleotide polymorphism; CHD: congenital heart disease. ${ }^{*}$ Adjusted for factors with statistical differences in Table 1.

of a perturbed maternal environment that is closely associated with CHD is maternal GDM [19]. GDM, with its hyperglycaemic milieu during the first trimester, is related to diabetic embryopathy, affecting the heart, great vessels, and neural tube [20]. GDM during the latter half of pregnancy is related to foetal macrosomia, cardiomyopathy, and an increased incidence of perinatal complications and mortality [21]. Maternal DM was found to be a risk factor for offspring
CHD in this study, which suggests the role of glucose in the causal pathway. Studies have indicated that the offspring of women with DM have similar risks for most types of CHD, and the increased risk of CHDs for them exceeded the increased risk of noncardiac diseases associated with maternal DM, which might be due to the impacts of maternal DM on general cardiac development very early in embryogenesis $[22,23]$. This is consistent with our results and implies that some degree of glycaemic control before and during pregnancy is necessary. In addition, obesity has been associated with a small increase in the risk of CHD [24]. Our study, however, did not support this conclusion. There was no significant difference in BMI between the control and case groups, which indicated that there were other vital factors impacting offspring CHD, especially for the women who developed DM during this pregnancy.

Many studies show that the occurrence and development of CHD might be associated with changes in transcription factors in offspring. Over the years, family-based studies have identified mutations in transcription factor genes controlling heart development, including NKX2.5, GATA4, and TBX5 [25]. These mutations are often observed in patients with CHD but are rarely found in patients without CHD [26]. In our study, NKX2.5 was proven to be associated with the incidence of CHD, and mutations at rs118026695 and rs2277923 were demonstrated to increase the risk of CHD in the univariate and multivariate analyses.

NKX2.5 is a member of the NK-2 family of homeodomain-containing transcription factors, which are highly conserved in many organisms [27]. It is a transcriptional regulator during early embryonic heart development and essential for the formation and maturation of the heart as well as the conduction system. Experiments indicate that the absence of NKX2.5 in mice results in embryonic lethality and arrested heart development [10]. In addition, more than 40 mutations of NKX2.5 have been found in CHD cases, and the $63 \mathrm{~A}>\mathrm{G}$ (rs2277923) polymorphism was one of the most intensively investigated sites [28]. Several studies have found that this polymorphism is significantly associated with $\mathrm{CHD}$ risk [11] and that this mutation is capable of changing mRNA structure and stability instead of the amino acid sequence of the encoded protein [29]. Moreover, the transcriptional activity of NKX2.5 is also related to CHD. Ouyang et al. revealed that the $63 \mathrm{~A}>\mathrm{G}$ mutation significantly reduced the transcriptional activity of NKX2.5 by $20 \%$, which might account for its association with CHD [11]. Some opposite results, however, were also found in CHD studies in which the SNPs of NKX2.5 at rs2277923 were not associated with the incidence of CHD in China [30]. The difference in results might be due to the choice of region, race, and CHD subtypes. Thus, further studies with large sample sizes are required to clarify this association.

The incidence of CHD is a result of both genetic and environmental factors. Their interactions are profoundly heterogeneous but may operate on common pathways. Nina et al. thought that glucose itself might exert a teratogenic effect via a signalling pathway regulating insulin sensitivity, which is also a key mediator of embryogenesis and early development [22]. Experimental studies found that 
TABLE 6: Interaction analysis of Maternal DM and NKX2.5 on CHD in offspring.

\begin{tabular}{|c|c|c|c|c|}
\hline Maternal DM & Genotype & $\beta$ & $P$ value & Adjusted OR $(95 \% \mathrm{CI})^{*}$ \\
\hline GDM during this pregnancy & rs118026695 & & & \\
\hline No & $\mathrm{T} / \mathrm{T}$ & & & 1 \\
\hline No & $\mathrm{C} / \mathrm{T}$ & $0.804\left(\beta_{\mathrm{g} 1}\right)$ & 0.001 & $2.23(1.50-3.33)$ \\
\hline No & $\mathrm{C} / \mathrm{C}$ & $21.324\left(\beta_{\mathrm{g} 2}\right)$ & 0.998 & $1.823 \mathrm{E} 9$ \\
\hline Yes & $\mathrm{T} / \mathrm{T}$ & $1.987\left(\beta_{\mathrm{e} 1)}\right.$ & 0.001 & $7.29(3.29-16.17)$ \\
\hline Yes & $\mathrm{C} / \mathrm{T}$ & $2.094\left(\beta_{\mathrm{e} 1} *_{\mathrm{g} 1}\right)$ & 0.008 & $8.12(1.71-38.51)$ \\
\hline Yes & $\mathrm{C} / \mathrm{C}$ & $0.430\left(\beta_{\mathrm{e} 1} *_{\mathrm{g} 2}\right)$ & 0.620 & $1.54(0.28-8.40)$ \\
\hline GDM in previous pregnancy experiences & rs118026695 & & & \\
\hline No & $\mathrm{T} / \mathrm{T}$ & & & 1 \\
\hline No & $\mathrm{C} / \mathrm{T}$ & $0.861\left(\beta_{\mathrm{g} 1}\right)$ & 0.001 & $2.37(1.59-3.52)$ \\
\hline No & $\mathrm{C} / \mathrm{C}$ & $1.496\left(\beta_{\mathrm{g} 2}\right)$ & 0.046 & $4.46(1.03-19.44)$ \\
\hline Yes & $\mathrm{T} / \mathrm{T}$ & $1.603\left(\beta_{\mathrm{e} 1)}\right.$ & 0.001 & $4.97(2.44-10.11)$ \\
\hline Yes & $\mathrm{C} / \mathrm{T}$ & $1.681\left(\beta_{\mathrm{e} 1} *_{\mathrm{g} 1}\right)$ & 0.074 & $5.37(0.85-33.87)$ \\
\hline Yes & $\mathrm{C} / \mathrm{C}$ & $21.345\left(\beta_{\mathrm{e} 1} *_{\mathrm{g} 2}\right)$ & 0.999 & $1.862 \mathrm{E} 9$ \\
\hline PGDM in the 3 months before this pregnancy & rs118026695 & & & \\
\hline No & $\mathrm{T} / \mathrm{T}$ & & & 1 \\
\hline No & $\mathrm{C} / \mathrm{T}$ & $0.826\left(\beta_{\mathrm{g} 1}\right)$ & 0.001 & $2.29(1.54-3.40)$ \\
\hline No & $\mathrm{C} / \mathrm{C}$ & $1.753\left(\beta_{\mathrm{g} 2}\right)$ & 0.013 & $5.77(1.45-23.05)$ \\
\hline Yes & $\mathrm{T} / \mathrm{T}$ & $1.971\left(\beta_{\mathrm{e} 1}\right)$ & 0.001 & $7.18(3.27-15.74)$ \\
\hline Yes & $\mathrm{C} / \mathrm{T}$ & $20.740\left(\beta_{\mathrm{e} 1} *_{\mathrm{g} 1}\right)$ & 0.998 & $1.017 \mathrm{E} 9$ \\
\hline Yes & $\mathrm{C} / \mathrm{C}$ & & & \\
\hline GDM during this pregnancy & rs2277923 & & & \\
\hline No & $\mathrm{C} / \mathrm{C}$ & & & 1 \\
\hline No & $\mathrm{T} / \mathrm{C}$ & $0.472\left(\beta_{\mathrm{g} 1}\right)$ & 0.007 & $1.60(1.14-2.26)$ \\
\hline No & $\mathrm{T} / \mathrm{T}$ & $0.703\left(\beta_{\mathrm{g} 2}\right)$ & 0.006 & $2.02(1.22-3.34)$ \\
\hline Yes & $\mathrm{C} / \mathrm{C}$ & $1.984\left(\beta_{\mathrm{e} 1)}\right.$ & 0.001 & $7.27(2.37-22.33)$ \\
\hline Yes & $\mathrm{T} / \mathrm{C}$ & $2.875(\beta \mathrm{e} 1 * \mathrm{~g} 1)$ & 0.001 & $17.72(5.79-54.24)$ \\
\hline Yes & $\mathrm{T} / \mathrm{T}$ & $0.338\left(\beta_{\mathrm{e} 1} *_{\mathrm{g} 2}\right)$ & 0.628 & $1.40(0.36-5.50)$ \\
\hline GDM in previous pregnancy experiences & rs2277923 & & & \\
\hline No & $\mathrm{C} / \mathrm{C}$ & & & 1 \\
\hline No & $\mathrm{T} / \mathrm{C}$ & $0.628\left(\beta_{\mathrm{g} 1}\right)$ & 0.001 & $1.88(1.33-2.65)$ \\
\hline No & $\mathrm{T} / \mathrm{T}$ & $0.715\left(\beta_{\mathrm{g} 2}\right)$ & 0.004 & $2.05(1.25-3.34)$ \\
\hline Yes & $\mathrm{C} / \mathrm{C}$ & $3.255\left(\beta_{\mathrm{e} 1)}\right.$ & 0.001 & $25.92(7.20-93.26)$ \\
\hline Yes & $\mathrm{T} / \mathrm{C}$ & $1.225\left(\beta_{\mathrm{e} 1} *_{\mathrm{g} 1}\right)$ & 0.005 & $3.41(1.44-80.07)$ \\
\hline Yes & $\mathrm{T} / \mathrm{T}$ & $0.867\left(\beta_{\mathrm{e} 1} *_{\mathrm{g} 2}\right)$ & 0.317 & $2.38(0.44-12.99)$ \\
\hline PGDM in the 3 months before this pregnancy & rs2277923 & & & \\
\hline No & $\mathrm{C} / \mathrm{C}$ & & & 1 \\
\hline No & $\mathrm{T} / \mathrm{C}$ & $0.579\left(\beta_{\mathrm{g} 1}\right)$ & 0.001 & $1.79(1.27-2.52)$ \\
\hline No & $\mathrm{T} / \mathrm{T}$ & $0.644\left(\beta_{\mathrm{g} 2}\right)$ & 0.009 & $1.90(1.17-3.09)$ \\
\hline Yes & $\mathrm{C} / \mathrm{C}$ & $3.592\left(\beta_{\mathrm{e} 1}\right)$ & 0.001 & $36.30(7.62-172.98)$ \\
\hline Yes & $\mathrm{T} / \mathrm{C}$ & $1.421\left(\beta_{\mathrm{e} 1} *_{\mathrm{g} 1}\right)$ & 0.002 & $4.14(1.67-10.27)$ \\
\hline Yes & $\mathrm{T} / \mathrm{T}$ & $21.312\left(\beta_{\mathrm{e} 1} *_{\mathrm{g} 2}\right)$ & 0.999 & $1.802 \mathrm{E} 9$ \\
\hline
\end{tabular}

DM: diabetes mellitus; CHD: congenital heart disease; GDM: gestational diabetes mellitus; PGDM: pregestational diabetes mellitus; OR: odds ratio; CI: confidence interval. *Adjusted for factors with statistical differences in Table 1.

hyperglycaemia in early pregnancy affected regulatory gene expression in the embryo for genes, such as Bmp4, Msx1, and Pax3, leading to cardiac neural crest cell death and an increased risk of CHD [31]. Whether the expression of $N K X 2.5$, an important transcriptional regulator in early car- diac development, is affected by hyperglycaemia is worthy of further experimental investigation. In addition, NKX2.5 is expressed in the first heart field (FHF) and the second heart field (SHF), the two distinct sources of cardiac progenitor cells contributing to different parts of the heart [32]. In mice, 
NKX2.5 repression of Bmp2/Smad1 signalling regulated SHF proliferation and outflow tract morphology [33]. In the cardiac fields of NKX2.5 mutants, failed SHF proliferation and OFT truncation were also found [34]. Similarly, hyperglycaemia was found to take part in the development of SHF, and the association with maternal diabetes mellitus was much stronger for anterior second heart field defects than for posterior second heart field defects when grouping the outflow tract malformations and the inflow tract malformations [19]. Based on the above, the interaction of maternal DM and NKX2.5 genetic variants deserves further exploration. To the best of our knowledge, this is the first study to explore the association of the interaction of maternal DM and NKX2.5 genetic variants with the risk of CHD in offspring.

Finally, we acknowledge important limitations in our study. This is a retrospective study, and recall bias is inevitable, even though we took measures to reduce it in sample selection and information collection. In addition, this study was aimed at Han Chinese individuals and was restricted geographically, so different ethnic populations and large sample sizes are required to confirm our results. Finally, the outcome of interest in this study was total CHD instead of specific CHD subtypes, which might contribute to the inaccuracy of the results.

\section{Conclusion}

In this study, we investigated the risk factors associated with CHD. We demonstrated that maternal DM, NKX2.5 variants, and their interaction were significantly associated with $\mathrm{CHD}$ in offspring. With the aim of preventing CHD, there is a need for women to control their glycaemic index during pregnancy and to screen for NKX2.5 mutations in their children if necessary.

\section{Data Availability}

The data used to support the findings of this study are included within the article.

\section{Conflicts of Interest}

The authors declare no conflict of interest, financial or otherwise.

\section{Acknowledgments}

The authors would like to thank the editors and reviewers for their suggestions and all colleagues working in Maternal and Child Health Promotion and Birth Defect Prevention Group. This study was funded by the National Natural Science Foundation Program of China (Grant No. 81803313, 81974019, 81970248), Natural Science Foundation Program of Hunan Province (Grant No. 2018JJ2551), Hunan Provincial Key Research and Development Program (Grant No. 2018SK2062 and 2018SK2063), National Key Research and Development Program of China (2018YFA0108700, 2017YFA0105602), The key program of Guangzhou science research plan (805212639211), and The Special Project of
Dengfeng Program of Guangdong Provincial People's Hospital (DFJH201812; KJ012019119).

\section{References}

[1] R. H. Anderson, "Has the congenitally malformed heart changed its face? Journey from understanding morphology to surgical cure in congenital heart disease," Circulation Research, vol. 120, no. 6, pp. 901-903, 2017.

[2] K. J. Jenkins, A. Correa, J. A. Feinstein et al., "Noninherited risk factors and congenital cardiovascular defects: current knowledge: a scientific statement from the american heart association council on cardiovascular disease in the young: endorsed by the american academy of pediatrics," Circulation, vol. 115, no. 23, pp. 2995-3014, 2007.

[3] T. van der Bom, A. C. Zomer, A. H. Zwinderman, F. J. Meijboom, B. J. Bouma, and B. J. Mulder, "The changing epidemiology of congenital heart disease," Nature Reviews Cardiology, vol. 8, no. 1, pp. 50-60, 2011.

[4] H. Melchior, D. Kurch-Bek, and M. Mund, "The prevalence of gestational diabetes," Deutsches Aerzteblatt Online, vol. 114, no. 24, pp. 412-418, 2017.

[5] J. G. Ray, T. E. O'Brien, and W. S. Chan, "Preconception care and the risk of congenital anomalies in the offspring of women with diabetes mellitus: a meta-analysis," QJM, vol. 94, no. 8, pp. 435-444, 2001.

[6] M. Basu and V. Garg, "Maternal hyperglycemia and fetal cardiac development: clinical impact and underlying mechanisms," Birth Defects Research, vol. 110, no. 20, pp. 15041516, 2018.

[7] M. W. Wessels and P. J. Willems, "Genetic factors in nonsyndromic congenital heart malformations," Clinical Genetics, vol. 78, no. 2, pp. 103-123, 2010.

[8] S. M. Reamon-Buettner and J. Borlak, "NKX2-5: an update on this hypermutable homeodomain protein and its role in human congenital heart disease (chd)," Human Mutation, vol. 31, no. 11, pp. 1185-1194, 2010.

[9] J. J. Schott, D. W. Benson, C. T. Basson et al., "Congenital heart disease caused by mutations in the transcription factor NKX25," Science, vol. 281, no. 5373, pp. 108-111, 1998.

[10] R. Terada, S. Warren, J. T. Lu, K. R. Chien, A. Wessels, and H. Kasahara, "Ablation of Nkx2-5 at mid-embryonic stage results in premature lethality and cardiac malformation," Cardiovascular Research, vol. 91, no. 2, pp. 289-299, 2011.

[11] P. Ouyang, E. Saarel, Y. Bai et al., "A de novo mutation in NKX2.5 associated with atrial septal defects, ventricular noncompaction, syncope and sudden death," international journal of clinical chemistry, vol. 412, no. 1-2, pp. 170-175, 2011.

[12] F. Sun and G. Liu, "Study on the expression of GATA4 and Nkx 2.5 genes in the heart development of fetal rats with gestational diabetes," in Proceedings of the Second Neonology Conference of Guangdong Medical Association, pp. 102-104, 2013.

[13] W. Li, J. Ren, X. Huang, F. Sun, and G. Liu, "Expression and significance of Nkx 2.5 in the heart development of gestational diabetic offspring," in Proceedings of the Third National Conference of Neonatal Physicians of the Chinese Medical Doctor Association, vol. 96, 2013.

[14] W. Li, G. Liu, S. Han, L. Song, and R. Qiang, "Expression and significance of Nkx 2.5 in fetal murine heart development during gestational diabetes," Journal of Guangzhou Medical University, vol. 3, pp. 18-22, 2015. 
[15] Y. Cao, J. Wang, C. Wei et al., "Genetic variations of NKX2-5 in sporadic atrial septal defect and ventricular septal defect in Chinese Yunnan population," Gene, vol. 575, no. 1, pp. 2933, 2016.

[16] S. Pang, J. Shan, Y. Qiao et al., "Genetic and functional analysis of the NKX2-5 gene promoter in patients with ventricular septal defects," Pediatric Cardiology, vol. 33, no. 8, pp. 1355-1361, 2012.

[17] M. den Hoed, M. Eijgelsheim, T. Esko et al., "Identification of heart rate-associated loci and their effects on cardiac conduction and rhythm disorders," Nature genetics, vol. 45, no. 6 , pp. 621-631, 2013.

[18] H. M. Wallace, "A model of gene-gene and gene-environment interactions and its implications for targeting environmental interventions by genotype," Theoretical Biology and Medical Modelling, vol. 3, no. 1, p. 35, 2006.

[19] S. Liu, K. S. Joseph, S. Lisonkova et al., "Association between maternal chronic conditions and congenital heart defects: a population-based cohort study," Circulation, vol. 128, no. 6, pp. 583-589, 2013.

[20] Z. Zhao and E. A. Reece, "New concepts in diabetic embryopathy," Clinics in Laboratory Medicine, vol. 33, no. 2, pp. 207233, 2013.

[21] K. Kc, S. Shakya, and H. Zhang, "Gestational diabetes mellitus and macrosomia: a literature review," Annals of Nutrition and Metabolism, vol. 66, no. 2, pp. 14-20, 2015.

[22] N. Oyen, L. J. Diaz, E. Leirgul et al., "Prepregnancy diabetes and offspring risk of congenital heart disease: a nationwide cohort study," Circulation, vol. 133, no. 23, pp. 2243-2253, 2016.

[23] R. M. Simeone, O. J. Devine, J. A. Marcinkevage et al., "Diabetes and congenital heart defects: a systematic review, metaanalysis, and modeling project," American Journal of Preventive Medicine, vol. 48, no. 2, pp. 195-204, 2015.

[24] K. J. Stothard, P. W. G. Tennant, R. Bell, and J. Rankin, "Maternal overweight and obesity and the risk of congenital anomalies: a systematic review and meta-analysis," Journal of the American Medical Association, vol. 301, no. 6, pp. 636650, 2009.

[25] B. G. Bruneau, "The developmental genetics of congenital heart disease," Nature, vol. 451, no. 7181, pp. 943-948, 2008.

[26] M. G. Posch, A. Perrot, K. Schmitt et al., "Mutations in gata 4, nkx 2.5 , creld 1 , and bmp 4 are infrequently found in patients with congenital cardiac septal defects," American journal of medical genetics. Part A, vol. 146a, no. 2, pp. 251-253, 2008.

[27] G. Ranganayakulu, D. A. Elliott, R. P. Harvey, and E. N. Olson, "Divergent roles for nk-2 class homeobox genes in cardiogenesis in flies and mice," Development (Cambridge, England), vol. 125, pp. 3037-3048, 1998.

[28] B. Stallmeyer, H. Fenge, U. Nowak-Gottl, and E. Schulze-Bahr, "Mutational spectrum in the cardiac transcription factor gene nkx 2.5 (csx) associated with congenital heart disease," Clinical genetics, vol. 78, no. 6, pp. 533-540, 2010.

[29] Z. E. Sauna and C. Kimchi-Sarfaty, "Understanding the contribution of synonymous mutations to human disease," Nature Reviews Genetics, vol. 12, no. 10, pp. 683-691, 2011.

[30] W. Zhang, X. Li, A. Shen, W. Jiao, X. Guan, and Z. Li, "Screening NXK2.5 mutation in a sample of 230 Han Chinese children with congenital heart diseases," Genetic Testing and Molecular Biomarkers, vol. 13, no. 2, pp. 159-162, 2009.
[31] S. D. Kumar, S. T. Dheen, and S. S. Tay, "Maternal diabetes induces congenital heart defects in mice by altering the expression of genes involved in cardiovascular development," Cardiovascular Diabetology, vol. 6, no. 1, p. 34, 2007.

[32] M. Buckingham, S. Meilhac, and S. Zaffran, "Building the mammalian heart from two sources of myocardial cells," Nature Reviews Genetics, vol. 6, no. 11, pp. 826-835, 2005.

[33] O. W. Prall, M. K. Menon, M. J. Solloway et al., "An Nkx25/Bmp2/Smad1 negative feedback loop controls heart progenitor specification and proliferation," Cell, vol. 128, no. 5, pp. 947-959, 2007.

[34] B. Zhou, A. Gise, Q. Ma, J. Rivera-Feliciano, and W. T. Pu, "Nkx2-5- and Isl1-expressing cardiac progenitors contribute to proepicardium," Biochemical and Biophysical Research Communications, vol. 375, no. 3, pp. 450-453, 2008. 